\title{
Gradient of the rhizosphere bioelectric potentials as a source of green energy
}

\author{
Kuleshova T.E. ${ }^{1,2 *}$, Gall N.R. ${ }^{1}$, Galushko A.S. ${ }^{2}$, Udalova O.R. ${ }^{2}$, Panova G.G. ${ }^{2}$ \\ ${ }^{1}$ Ioffe Institute, St. Petersburg, Russia \\ ${ }^{2}$ Agrophysical Research Institute, St. Petersburg, Russia \\ * email: www.piter.ru@bk.ru
}

Bioelectric potentials (BEP) generated during the life of plants along the root system can become the basis for a new green energy resource. The aim of this work was to determine the gradient of bioelectric potentials generated in the root zone and to develop a construction of a plant fuel cell. Leningradsky spring barley (Hordeum vulgare L.) was chosen to study the potential gradient in the soil. Porous corrosion-resistant electrodes were placed horizontally with a pitch of $50 \mathrm{~mm}$ in the $400 \mathrm{~mm}$ high chamber for growing, and registration of the potential difference was carried out automatically every 15 minutes during the entire barley growing period. The potential difference in soil decreased from $220 \mathrm{mV}$ to $10 \mathrm{mV}$ with decrease in the interelectrode distance and drops to zero in about 20 days. The BEP increase up to $300 \mathrm{mV}$ has been observed on the $35^{\text {th }}$ day of vegetation, as the root system grows along the electrodes. It could be assumed that the root system increased the intensity of physicochemical and biological processes associated with ion transport in the rhizosphere. Soil-free type of a plant fuel cell was constructed where the electrodes were placed in the position with the observed maximum potential difference - between the root collar and the tips. Lettuce (Lactuca sativa L.) cultivated by the panoponics method was the object of research. A similar dynamics of the BEP in different variants was observed - the generation of $30-100 \mathrm{mV}$ voltage at the beginning, gradual decrease on the 5 th day of vegetation, smooth increase on the 10th day and then stabilization. The power removed from the cell was $0.04 \mu \mathrm{W}$ at a load of $10 \mathrm{kOm}$. Thus, the electrogenic properties of the plant and the oxidation-reduction reactions accompanying the life of plants in the root environment can be considered as an independent source of energy, the generation of which is carried out throughout the entire growing season. 